\section{Marina Peduzzi'}

Maria Luiza Anselmi"

Ivan França Junior'II

Claudia Benedita dos Santosiv

\section{$Q$ uality of procedures delivered by nursing assistants}

\begin{abstract}
OBJECTIVE: To assess the quality of nursing care provided in inhalation, peripheral venipuncture, and administration of intra-muscular medication procedures in the context of professional training of nursing assistants.

METHODS: A cross-sectional study was carried out in two phases among nursing staff (nurse assistants as well as unlicensed nursing personnel), in three hospitals in the state of Bahia, Northeastern Brazil, in October and December 2001 and 2002. Data was collected by means of direct observation of task performance and analysis of the median values of performance. A convenience sample was stratified according to professional category and work unit.
\end{abstract}

RESULTS: There was a quality improvement or maintenance while performing the procedure of inhalation, with an overall median score equal to or above $70 \%$. Median scores were reduced for peripheral venipuncture and administration of intra-muscular medication. Analysis of the differences in the procedures indicated that performance improved regarding basic procedural steps but worsened regarding the interaction with the patient. As to the nursing teams, those in Hospital 1, where there were better working conditions, had the best performance, and those in Hospital 2, where there were the worst working conditions, showed the worst performance.

CONCLUSIONS: Educational processes among nurse assistants implemented per se in poor working conditions are not able to bring about quality improvement of professional performance.

KEYW O RD S: N urses's aides, education. Nursing staff hospital, health manpower. $Q$ uality. $Q$ uality of health care. Education, nursing.
Departamento de Orientação Profissional. Escola de Enfermagem. Universidade de São Paulo (USP). São Paulo, SP, Brasil

" Departamento de Enfermagem Geral e Especializada. Escola de Enfermagem de Ribeirão Preto (EERP). USP. Ribeirão Preto, $\mathrm{SP}$, Brasil

III Departamento de Saúde Materno-Infantil. Faculdade de Saúde Pública. USP. São Paulo, SP, Brasil

IV Departamento de Enfermagem MaternoInfantil e Saúde Pública. EERP-USP. Ribeirão Preto, SP, Brasil

\author{
Correspondence: \\ Marina Peduzzi \\ Departamento de O rientação Profissional \\ Escola de Enfermagem da USP \\ Av. Dr. Enéas de Carvalho Aguiar, 419 \\ 05403-000 São Paulo, SP, Brasil \\ E-mail: marinape@usp.br
}




\section{INTRO DUCTION}

There are different classes of nursing workers in Brazil, with important participation of nurse assistants or nurses without formal and regular technical education. These workers were $30 \%$ of the nursing workforce in 1999, * and $15.1 \%$ in 2002.** The current Brazilian legislation of the profession (Law 7,498/86) prohibits the work of unlicensed nurses. Nurse assistants, who have one year of formal technical education and at least complete fundamental education, account for most nursing workers, $62.7 \%$.**

In the 80's and 90's, public health policies, especially in human resources, made changes in the internal formation of health teams, encouraging personnel education for technical and assistant levels. In nursing, this change was conducted through projects such as Programa de Formação de Pessoal de Nível Médio e de Nível Elementar (Personnel Education Program for Elementary and Technician, known as Projeto Larga Escala (PLE) and, more recently, Projeto de Profissionalização dos Trabalhadores da Área de Enfermagem (PROFAE) (Project for Professionalizing Nursing Workers).

PROFAE is an internationally accredited Project introduced by the Health Ministry in 2000, involving about 5,505 cities all over the country. Aiming at professionalizing 225 thousand nursing workers without formal technical education (unlicensed nurses and others), the Project also provided education to 90 thousand nursing technicians and the pedagogical education of 12 thousand professors of the courses. ${ }^{5}$

However, not much is known about the real quality of nursing workers performance. Poor performance in nursing technical interventions may offer risks for users, jeopardizing the quality of health care and increasing costs.

There are few publications on the issue in the literature. In the beginning of the 80 's an article on the technique of intra-muscular injection was published, ${ }^{1}$ and another on venipuncture was published in 2005 using the same methodology we have used in the current research. ${ }^{8}$ Other publications identified, were about nursing techniques on procedure performance rather than the workers performance or its effects on care quality. Studies on iatrogenic occurrences or critical incidents are more common because they have immediate and undesirable consequences to patients. Such occurrences may be connected with several reasons: medication, patient's falling down; catheters, probes, and drains, equipments and materials, and others.***

Considering there are not many national studies assessing the quality of nursing workers performance, and the recent development of PROFAE; the present article aimed at assessing the changes in quality of nursing care provided in inhalation, peripheral venipuncture and intra-muscular medication in the context of professional qualification of these workers in the Project.

\section{METHODS}

The research was conducted in two phases: two crosssectional studies, one before nursing workers took part in professional courses at PROFAE (October $1^{\text {st }}$ to December $\left.7^{\text {th }}, 2001\right)$ and another afterwards (October $21^{\text {st }}$ to December $7^{\text {th }}, 2002$ ).

Research was developed in three health services in a Brazilian northeastern province: Bahia (services 1, 2, 3 ). Inclusion criteria was to have 10 or more nursing workers without formal and regular technical education taking part at PROFAE and that performed the techniques studied. This criteria followed the need to document the changes occurred in the context of PROFAE.

Service 1 is located in a city with more than 250 thousand inhabitants, which is part of the Unified Health System (SUS). The local system had 117 ambulatory services ( 88 public, 29 private) and 11 hospitals (seven hired private hospitals, two state hospitals, one municipal hospital, and one philanthropic hospital). The philanthropic hospital researched in phase 2 of the study had 166 beds; 10,086 admissions/year; occupation rate was $80.4 \%$ and there were 171 nursing workers (41 unlicensed nurses, 97 nurse assistants, 22 nurse technicians, and 11 nurses). This picture represented $34.8 \%$ and $62.1 \%$ of the estimated number of nurses and nursing assistants/technicians respectively. Nursing monitoring was conducted among nurses, assistants and technicians, however, continued professional development was not offered.

Service 2, located in a town with more than 20 thousand inhabitants, had 10 ambulatory unities (eight

\footnotetext{
* Ministério da Saúde, Secretaria de Políticas de Saúde, Secretaria de Gestão de Investimentos em Saúde. Dossiê: mercado de trabalho em enfermagem no Brasil: PROFAE - Programa de formação de trabalhadores na área de enfermagem. Brasília (DF); 1999. **M inistério da Saúde; Departamento de Informática do SUS. Anuário estatístico de saúde do Brasil. Brasília (DF): Ministério da Saúde; 2002. p. 289-90.

***Silva SC. O corrências iatrogênicas em unidade de terapia intensiva: impacto na gravidade do paciente e na carga de trabalho de enfermagem [tese de doutorado]. São Paulo: Escola de Enfermagem da Universidade de São Paulo; 2003.
} 
public, two private) and a philanthropic hospital. The latter hospital was studied in phase 2 of the research, it had 73 beds; 1,512 admissions/year; occupation rate was $25.7 \%$, and there were 25 nursing workers (nine unlicensed nurses, 15 nurse assistants, one nurse). This picture represented $20 \%$ and $62.5 \%$ of the amount estimated for nurses and nursing assistants respectively. The only nurse met during phase 1 of the study left the service during data collection in phase 2, and the nursing work coordination in this period was under the responsibility of a nursing assistant. Neither monitoring nor continued professional development was observed or reported.

Service 3, located in a town with more than 70 thousand inhabitants, had 37 ambulatory services (29 public and seven private), and one philanthropic hospital. This hospital was researched and in phase 2 of the study it had 225 beds; 12,163 admissions/year; occupation rate was $69.9 \%$, and there were 180 nursing workers (47 unlicensed nurses, 76 nurse assistants, 52 technicians, and five nurses). This picture represented $14 \%$ and $69.2 \%$ of the estimated amount of nurses and nursing assistants/technicians. Neither supervision nor continued professional development was observed in the service.

The study population from these services was formed by unlicensed nurses taking or not the courses at PROFAE, graduated nursing assistants taking or not the courses at PROFAE and nursing technicians. All of them provided the studied techniques: peripheral venipuncture for applying medication, intra-muscular medication and inhalation.

A convenience sample was stratified according to professional category and work unit. The maximum size of the sample of workers observed was 15 with a $30 \%$ safety margin, resulting in 21 subjects for professional category, per service. In services where the number of workers in a certain category was inferior to 21 , all workers have been considered. In establishments with more than 21 workers, sample was made at random. In the nursing assistant category a weighted sample was performed according to each stratus, because in the second phase of the field research it was divided into three stratus (graduated assistant; undergraduate assistant not currently studying; student assistant). Samples were considered independently because the individuals observed in the two phases of the research were not necessarily the same.

Data collection was carried out through observed individually the performance of the three techniques studied, with at least three observations of the individuals from the nursing workers samples. An assess- ment tool was used, describing the procedures selected step by step, considering excellence standards. Description of each step was followed by three alternatives: correct, incorrect, does not apply, and a space for observations. Direct observations were performed by nurses, who were selected and trained specifically for the study.

The three techniques were selected because they are part of the every day work in nursing and because the pilot study showed that they were performed both by unlicensed professionals, nursing assistants, and technicians.

The assessment of changes in quality of the performance of nursing techniques in the two phases of the study was conducted based on measuring performance and assessing occurrences (rights and/or wrongs).

To assess each procedure, four cores of nursing techniques were created: a basic procedural core (essential and necessary steps for performing the technique), a technical core (steps regarding anti-sepsis and other steps that were essentially technical), an interaction with the patient core (steps regarding interaction and user observation) and a management core (steps regarding physical and material resources, and record). The basic procedural core however, is also technical it is formed by steps that are essential to therapy or diagnosis. For each core, percentage scores were assessed resulting from the sum of steps. Median values for global performance were considered in the analysis together with the values of each core to each technique. Based on other studies, ${ }^{1,8}$ we have defined as satisfactory, performances with overall median score equal to or above $70 \%$, for each technique.

In the Table 1 the steps corresponding to each core for each technique researched are present.

To assess the significance of difference between phases 1 and 2 of the study, non-parametric median test was used. ${ }^{3}$ Differences with significance level equal or inferior to $5 \%$ were considered significant.

Theoretical reference was based on studies of work in health and nursing that view both work and education as social practices. The quality of nursing care is a result of a reciprocal correlation influenced both by professional qualification and working conditions. ${ }^{7}$

Based on this theoretical reference, the hypothesis that guided data collection and analysis was formulated: technical qualification leads to better professional performance in nursing workers, with suitable working conditions in terms of personnel cadre and 
Table 1 - Cores and respective steps to each studied technique. Bahia, Brazil, 2001-2002.

\begin{tabular}{|c|c|c|c|}
\hline \multirow[t]{2}{*}{ Core } & \multicolumn{3}{|c|}{ Technique } \\
\hline & Inhalation & Venipuncture & Intra-muscular medication \\
\hline $\begin{array}{l}\text { Basic } \\
\text { Procedural }\end{array}$ & $\begin{array}{l}\text { - Put prescribed solution in the inhaler } \\
\text { - Connect the inhaler with the extension } \\
\text { of flow meter, compressor or similar } \\
\text { - O pen the valve, compressor or similar } \\
\text { - Turn the flow meter, compressor or } \\
\text { similar off and withdraw the inhaler }\end{array}$ & $\begin{array}{l}\text { - Read medical prescription } \\
\text { - Test syringe and connect it to a needle } \\
\text { - Prepare medication } \\
\text { - Identify puncture site } \\
\text { - Place tourniquet } \\
\text { - Introduce needle keeping bevel side } \\
\text { of it up } \\
\text { - Check if needle has entered the vein } \\
\text { - Remove tourniquet and start application } \\
\text { - Place cotton pad on the site and remo- } \\
\text { ve needle }\end{array}$ & $\begin{array}{l}\text { - Read medical prescription } \\
\text { - Dilute liquid if necessary and inhale it } \\
\text { - Identify puncture site } \\
\text { - Position the syringe at a } 90 \text {-degree angle } \\
\text { - Place cotton pad on the site and remo- } \\
\text { ve needle }\end{array}$ \\
\hline Technical & $\begin{array}{l}\text { - Read medical prescription } \\
\text { - Wash hands } \\
\text { - Gather material } \\
\text { - Check if inhaler is working } \\
\text { - Guide patient to hold inhaler } \\
\text { - Wash inhaler and place it in } \\
\text { disinfecting solution } \\
\text { - Wash hands }\end{array}$ & $\begin{array}{l}\text { - Wash hands } \\
\text { - Gather material } \\
\text { - Put gloves on } \\
\text { - Perform site anti-sepsis } \\
\text { - Take gloves off } \\
\text { - Wash hands }\end{array}$ & $\begin{array}{l}\text { - Wash hands } \\
\text { - Gather material } \\
\text { - Take and clean bottle and/or ampoule } \\
\text { - Test syringe and connect needle } \\
\text { - Replace needle placing one used for } \\
\text { IM injection } \\
\text { - Perform site antisepsis } \\
\text { - Stretch the skin of the injection site taut } \\
\text { - Aspirate syringe lightly } \\
\text { - Slowly inject the medication } \\
\text { - Apply gentle pressure on the site } \\
\text { - Wash hands }\end{array}$ \\
\hline $\begin{array}{l}\text { Interaction } \\
\text { with patients }\end{array}$ & $\begin{array}{l}\text { - Explain to the patient what will be } \\
\text { done } \\
\text { - Position the patient } \\
\text { - Give guidelines to the patients }\end{array}$ & $\begin{array}{l}\text { - Explain to the patient what will be done } \\
\text { - Position the patient } \\
\text { - Observe the punctured site } \\
\text { - Give guidelines to the patients }\end{array}$ & $\begin{array}{l}\text { - Explain to the patient what will be done } \\
\text { - Give guidelines to the patients }\end{array}$ \\
\hline Management & - Record the procedure & $\begin{array}{l}\text { - Rearrange patient's unity } \\
\text { - Collect material } \\
\text { - Record procedure }\end{array}$ & $\begin{array}{l}\text { - Collect material } \\
\text { - Record procedure }\end{array}$ \\
\hline
\end{tabular}

the development of nursing monitoring and continued professional development.

The research project was approved by the Ethical Committee in Research of the Escola de Enfermagem of Universidade de São Paulo. Authorization to conduct the research was obtained with the services' direction and written consent was given by all subjects observed, assuring anonymity both of the institutions and professionals involved.

\section{RESU LTS}

Tables 2 to 4 present the changes in performance of the nursing teams for each technique studied in each of the three services in phases 1 and 2 from the research, according to the overall median score and the respective core.

In the assessment of performance changes during inhalation technique, overall median score did not change in services 1 and 2 between both phases of the study. Overall median score in service 3 improved in phase 2 (Table 2).

Regarding the core, there was a positive change in performance of the basic procedural core and a negative change in the interaction with the patient core in the three services between both phases of the study.
In the technical core, services 1 and 2 did not present changes in nursing team performance whereas service 3 presented a negative variation. Management core did not change in services 1 and 3 , and worsened in service 2 (Table 2).

Assessment of overall median score of the performance of peripheral venipuncture technique demonstrates that in the three services results in phase 2 were worse, a negative change occurred in the performance of this technique (Table 3).

The basic procedural core remained with the same quality level and the interaction with the patient core worsened between the two phases of the study in the three services. Technical core did not change in service 1 and worsened in services 2 and 3. Management core did not change in services 1 and 3 with median maintained at $100 \%$, whereas in service 2 it worsened (Table 3).

Overall median score result in intra-muscular medication technique also showed poorer performance in phase 2 in the three services studied (Table 4).

Regarding intra-muscular medication, a good performance of the basic procedural core was observed in the two phases of the research in services 1 and 3 , although service 3 presented statistically significant worsening, 
Table 2 - Distribution of median scores (\%) of changes observed in inhalation technique performance in phases 1 and 2 of the study, according to the cores and services studied. Bahia, Brazil, 2001-2002.

\begin{tabular}{|c|c|c|c|c|c|c|c|c|c|c|}
\hline \multirow[t]{2}{*}{ Service } & \multicolumn{2}{|c|}{ Basic procedural } & Interaction & with patients & \multicolumn{2}{|c|}{$\begin{array}{c}\text { Cores } \\
\text { Technical }\end{array}$} & \multicolumn{2}{|c|}{ Management } & \multirow{2}{*}{\multicolumn{2}{|c|}{$\begin{array}{c}\text { Overall median } \\
\text { score } \\
\text { Phase } 1 \text { Phase } 2\end{array}$}} \\
\hline & Phase 1 & Phase 2 & Phase 1 & Phase 2 & Phase 1 & Phase 2 & Phase 1 & Phase 2 & & \\
\hline 1 & $87 \%$ & $100 \%$ & $77 \%$ & $48 \%$ & $80 \%$ & $68 \%$ & $100 \%$ & $100 \%$ & $82 \%$ & $74 \%$ \\
\hline 2 & $25 \%$ & $92 \%$ & $76 \%$ & $33 \%$ & $62 \%$ & $60 \%$ & $100 \%$ & $33 \%$ & $60 \%$ & $60 \%$ \\
\hline 3 & $25 \%$ & $95 \%$ & $100 \%$ & $\downarrow \quad 47 \%$ & $71 \%$ & $62 \%$ & $67 \%$ & $100 \%$ & $60 \%$ & $\uparrow \quad 67 \%$ \\
\hline
\end{tabular}

Subtitle: $\downarrow$ Negative change $(p<0.05) ; \quad \uparrow$ Positive change $(p<0.05) ; \quad=$ No changes

with median varying from $97 \%$ to $92 \%$. In service 2 , a worsening in performance was observed and median changed from $100 \%$ to $76 \%$, and this is the only situation in which this basic procedural core presented negative result. In the interaction with the patient core, negative variation occurred in the three services. In the technical core, negative variation occurred in services 2 and 3, and remained the same in service 1 . In the management core, performance worsened in service 2 , and service 1 and 3 maintained the median at $100 \%$ in both phases of the study (Table 4).

\section{DISCUSSION}

The present study was able to measure through direct observation the performance of nursing workers in specific techniques. Additionally, the initial performance was recorded together with its changes after educational and professional investments such as PROFAE. These empirical and methodology advances may lead to further improvements on nursing performances in other working contexts, apart from PROFAE. However, it is important to point out the limitations of this investigation.

First of all, as the inclusion criteria of services in the sample were highly selective, it is impossible to generalize their results. However, it is possible to assume that this sample can represent philanthropic private services that have agreements with SUS with nursing workers without formal and regular technical qualification in the State of Bahia.

Second of all, the small sample of subjects hindered more complex statistical analysis that could identify factors associated with better or worse performance, making the necessary changes in case of misunderstandings.

Comparison of workers performance between phases 1 and 2 of the investigation demonstrates that only in inhalation technique either a positive change occurred or the quality remained the same; in peripheral venipuncture technique and in intra-muscular medication negative changes occurred in the overall median score.

Although peripheral venipuncture has presented negative changes in services 1 and 3, both have maintained a satisfactory performance. Service 1 presents variation from 87 to $84 \%$, and service 3 presents variation from 80 to $71 \%$. Likewise, the intra-muscular medication technique for service 1 presented negative change, however, median score varied from $83 \%$ to $78 \%$.

Study $^{8}$ on the peripheral venipuncture identified that nursing professionals are performing the techniques with similar percentiles of success and failure, with an overall median of $78 \%$. Another study ${ }^{1}$ on intramuscular injection demonstrated that the performance of this technique varied from $83.5 \%$ successes in the ambulatory of a teaching hospital to $76.7 \%$ in a primary care unity.

Analysis of the quality of performance in the techniques after the beginning of professional qualification showed a different behavior among the four

Table 3 - Distribution of median scores (\%) of the changes observed in performance of the venipuncture technique performance, in phases 1 and 2 of the study, according to cores and services studied. Bahia, Brazil, 2001-2002.

\begin{tabular}{|c|c|c|c|c|c|c|c|c|c|c|}
\hline \multirow[t]{2}{*}{$\overline{\text { Service }}$} & \multicolumn{2}{|c|}{ Basic procedural } & \multirow{2}{*}{$\begin{array}{r}\text { Interaction } \\
\text { Phase } 1\end{array}$} & \multirow{2}{*}{$\begin{array}{c}\text { with patients } \\
\text { Phase } 2\end{array}$} & \multicolumn{2}{|c|}{$\begin{array}{c}\text { Cores } \\
\text { Technical }\end{array}$} & \multicolumn{2}{|c|}{ M anagement } & \multirow{2}{*}{\multicolumn{2}{|c|}{$\begin{array}{c}\text { Overal median } \\
\text { score } \\
\text { Phase } 1 \text { Phase 2 }\end{array}$}} \\
\hline & Phase 1 & Phase 2 & & & Phase 1 & Phase 2 & Phase 1 & Phase 2 & & \\
\hline 1 & $98 \%$ & $99 \%$ & $87 \%$ & $65 \%$ & $70 \%$ & $67 \%$ & $100 \%$ & $100 \%$ & $87 \%$ & $84 \%$ \\
\hline 2 & $96 \%$ & $85 \%$ & $75 \%$ & $44 \%$ & $37 \%$ & $21 \%$ & $94 \%$ & $73 \%$ & $76 \%$ & $62 \%$ \\
\hline 3 & $96 \%$ & $100 \%$ & $98 \%$ & $\downarrow \quad 60 \%$ & $39 \%$ & $33 \%$ & $100 \%$ & $100 \%$ & $80 \%$ & $71 \%$ \\
\hline
\end{tabular}


Table 4 - Distribution of median scores (\%) of the changes observed in performance of the intramuscular medication technique, in phases 1 and 2 of the study, according to cores and services studied. Bahia, Brazil, 2001-2002.

\begin{tabular}{|c|c|c|c|c|c|c|c|c|c|c|}
\hline \multirow[t]{2}{*}{ Service } & \multicolumn{2}{|c|}{ Basic procedural } & \multicolumn{2}{|c|}{ Interaction with patients } & \multicolumn{2}{|c|}{$\begin{array}{c}\text { Cores } \\
\text { Technical }\end{array}$} & \multicolumn{2}{|c|}{ Management } & \multirow{2}{*}{\multicolumn{2}{|c|}{$\begin{array}{c}\text { O verall median } \\
\text { score } \\
\text { Phase } 1 \text { Phase } 2\end{array}$}} \\
\hline & Phase 1 & Phase 2 & Phase 1 & Phase 2 & Phase 1 & Phase 2 & Phase 1 & Phase 2 & & \\
\hline 1 & $100 \%$ & $100 \%$ & $80 \%$ & $32 \%$ & $73 \%$ & $73 \%$ & $100 \%$ & $100 \%$ & $83 \%$ & $78 \%$ \\
\hline 2 & $100 \%$ & $76 \%$ & $77 \%$ & $10 \%$ & $100 \%$ & $49 \%$ & $74 \%$ & $60 \%$ & $81 \%$ & $53 \%$ \\
\hline 3 & $97 \%$ & $92 \%$ & $100 \%$ & $\downarrow \quad 16 \%$ & 75 & $65 \%$ & $100 \%$ & $100 \%$ & $83 \%$ & $68 \%$ \\
\hline
\end{tabular}

cores of the procedure, especially the basic procedural core and the interaction with the patients core. It was observed that the maintenance or improvement in performance that occurred in basic procedural core was followed by a decrease in performance in the interaction with the patient core in nursing teams from the three services. None of the teams presented median equal to or above $70 \%$ in the second phase of the study. In the three procedures, communication dimension is particularly represented by two steps: "patients are told what will be done", when the technique starts, and "guidelines are given to the patients", when it finishes.

Steps regarding communication in the studies mentioned ${ }^{1,8}$ show compromised performance. Regarding the step "explain procedure to the client", results obtained by Torres ${ }^{8}$ showed partially satisfactory performance of nursing assistants (median $100 \%$, percentile $25=33$ ) and for nurses and technicians, unsatisfactory performance. In the step "Guide the clients regarding necessary cares for puncture" the three categories presented unsatisfactory result.

Also in the technical core, steps regarding anti-sepsis were compromised in both phases of the study, with negative variation in services 2 and 3. Only in service 1 the performance of nursing team did not change in terms of quality in the technical core, and, only in intra-muscular medication median presented a satisfactory level, 73\%. In peripheral venipuncture performance level varied in the technical core from $70 \%$ to $67 \%$, and in inhalation it varied from $80 \%$ to $68 \%$. Anti-sepsis steps such as: washing the hands before and after the procedure; washing the inhaler and putting it in disinfecting solution; make anti-sepsis of the site; and others are part of the technical core. To be successful, they require, in addition to knowledge, skills and attitude of the worker, material resources, and infrastructure. We observed the absence of sinks in the wards studied, which made it difficult to wash the hands.

In the Almeida et al $^{1}$ study the "hand washing" step was not done or incorrectly done by all people in the two unities studied. According to Torres, ${ }^{8}$ "wash the hands before the procedure" presented partially satisfactory performance by nurses and unsatisfactory performance by nurse assistants and technicians, and "wash the hands after the procedure" presented unsatisfactory performance in all categories.

Analysis of the differences among the four cores showed that the best performance in all the three techniques occurred in the basic procedural core, which improved in inhalation in the three services, and remained satisfactory for venipuncture and intra-muscular medication for all but service 2 . Nursing workers tend to perform correctly the essential steps of the basic procedural core without which the technique cannot be conducted. On the other hand, the worst performance was observed in the interaction with the patient core in the techniques in the three services, with more expressive negative change between the two phases.

In the three procedures studied, negative variations were observed in performing the techniques by the nursing team of service 2 . This health service presented poorer organization of the nursing work. In phase 1 of the research, the nursing team had only unlicensed nurses and one nurse. In phase 2 , there were unlicensed nurses and $62.2 \%$ of nursing assistants graduated by PROFAE, one of them was responsible for the nursing coordination. Just as the other two services studied, service 2 did not have continued professional development, and there was no nursing monitoring. Bed occupancy rate decreased between the two phases of the research varying from $29.9 \%$ to $25.7 \%$.

On the other hand, the nursing team from service 1 presented improved performance, and although there was no continued professional development in the premises, the team was the best and there was an effective monitoring program.

Thus, features of the health services and the working conditions especially the nursing cadre, monitoring, and continued professional development, 
influence the results that educational projects to nursing workers have regarding the quality of their services. Educational approaches focusing on individual training that do not take the work environment, and the possibility to move and migrate workers into account, reach limited results. ${ }^{6}$

Technical qualification promoted by PROFAE, both for unlicensed nurses and assistants, occurs outside the health services, in professional education establishments. This may have been a limitation regarding their effects in the quality of performance of workers in the work environment, since condition in work and in education may have been difficult to be matched. Additionally, in the study period, only part of the nursing workers received professional qualification: 12 unlicensed nurses in service 1 (22.6\%), 15 unlicensed nurses in service 2 (62.2\%), and 47 unlicensed nurses in service $3(50 \%)$ of the total for each service in phase 1 were trained as nursing assistants, reducing the impacts on the team.

Although the educational projects are highlighted as being a solution for problems in human resources in health and nursing, there are several limitations and obstacles for effective strategies based on personnel training. The conflicts between immediate needs and the long education period, and the suitable correlation between investments on infrastructure and on health personnel are among them. ${ }^{4} \mathrm{~A}$ study conducted by the Pan American Health Organization,* reports that despite the importance of personnel training and of investments made in countries of Latin America and the Caribbean, the expected results have not been reached both in the service and in changing the health systems. The study also points out that old pedagogical paradigms are among the problems.

Based on the results found in the present study, we have concluded that the impacts of PROFAE on the quality of nursing performance are influenced by work contexts. Thus, better professional performance was observed in service 1 that presented better working conditions, even though just some of the unlicensed nurses have received qualification as nursing assistants. Also, the educational processes of nursing assistants implemented per se, in poor working conditions regarding personnel cadre, nursing supervision and continued education are not able to make positive changes in the quality of professional performance other than in the basic procedural core, leaving unattended other technical, management, and communication dimensions.

There is the need to link educational processes of health workers in the work processes that they actually do, and the management of work as recommended by the idea of permanent health education. ${ }^{2}$ Current theoretical studies on teaching-learning show that professionals cannot mechanically transport what they have learnt in class to a real work situation.

The present study showed the need to produce empirical research assessing the performance of nursing techniques, once they are a relevant aspect of this practice and there are few publications on this issue. There is also a need for empirical research on the assessment of educational processes to health workers in the quality of work with particular interest in recognizing the variables that can interfere in the interface between the formation and use of human resources.

\section{REFEREN CES}

1. Almeida MCP, Gomes DLS, Silva E. Avaliação da técnica de injeção intramuscular através do checklist. Rev Bras Enfermagem. 1980;33:428-42.

2. Ceccim RB, Feuerwerker LCM. O quadrilátero da formação para a área da saúde: ensino, gestão, atenção e controle social. Physis (Rio J). 2004;14:41-65.
3. Hollander M, Wolfe DA. Nonparametric statistical methods. New York (NY): Wiley; 1973.

4. Hongoro $C$, McPake $B$. How to bridge the gap in human resources for health. Lancet. 2004;364:1451-6. 
5. Ministério da Saúde. Projeto PROFAE. O ferta de qualificação é necessária para melhora a atenção à saúde. Formação. 2001;1:7-12.

6. Narasimhan $\mathrm{V}$, Brown $\mathrm{H}$, Pablos-Mendez A, Adams $O$, Dussault $G$, Elzinga $G$, et al. Responding to the global human resources crisis. Lancet. 2004;363(9419):1469-72.
7. Schraiber LB, Nemes MIB. Processo de trabalho e avaliação de serviços de saúde. Cad FUNDAP. 1996;(19):106-30.

8. Torres MM, Andrade D, Santos CB. Punção venosa periférica: avaliação de desempenho dos profissionais de enfermagem. Rev Latinoam Enfermagem. 2005;13:299-304.

Research conducted at the Nursing School of the University of São Paulo (USP) and Nursing School of U SP in Ribeirão Preto. Financed by the Ministry of Health, Secretaria de Gestão do Trabalho e da Educação na Saúde (Secretariat of Work Management and Health Education) (MS/SGTES - Process n. ED 06754/201) 